\title{
Variações terminológicas no campo Tradução Audiovisual: análise dos termos legendação, legendagem e tradução de/ para legendas.
}

\section{Variation in terminology of Audiovisual Translation: an analysis of three Portuguese technical terms: legendação, legendagem and tradução de/para legendas}

\author{
Arlene Koglin ${ }^{1}$ \\ Sila Marisa de Oliveira ${ }^{2}$
}

A constituição de uma terminologia própria marca, em toda ciência, o advento ou 0 desenvolvimento de uma conceitualização nova, assinalando, assim, um momento decisivo de sua história. Poder-se-ia mesmo dizer que a história particular de uma ciência se resume na de seus termos específicos.

Benveniste

Abstract: This paper aims at both discussing and mapping terminology used in the Audiovisual Translation area with emphasis on subtitling. By focusing on three

\footnotetext{
${ }^{1}$ Doutoranda do Programa de Pós-Graduação em Estudos Linguísticos da Universidade Federal de Minas Gerais. E-mail: arlenekoglin@yahoo.com.br

2 Mestre em Estudos da Tradução pelo Programa de Pós-Graduação em Estudos da Tradução da Universidade Federal de Santa Catarina. E-mail: silamari@gmail.com
} 
260

Koglin, A. e OlivelRA, S. M. - Variações terminológicas no campo Tradução Audiovisual: análise dos termos legendação, legendagem e tradução de/ para legendas.

Portuguese technical terms (legendagem, legendação, tradução de/ para legendas), data were collected from specialized texts published online. Data analysis shows that those terms are either used ambiguously or referring to different concepts. The results suggest an urgent demand for establishing terminological homogeneity in this research field in the Brazilian context.

Keywords: terminology; subtitling; audiovisual translation.

Resumo: Este artigo objetiva discutir e mapear, em publicações eletrônicas, a terminologia usada na Tradução Audiovisual, com ênfase no ramo da legendagem/legendação. A pesquisa foi realizada nos títulos de teses, dissertações e artigos com os termos legendagem, legendação e tradução de/para legendas. A análise revela uso indiscriminado dos termos, o que demonstra a necessidade premente de estabelecer homogeneidade terminológica neste campo de pesquisa acadêmica.

Palavras-chave: terminologia; legendação/legendagem; Tradução Audiovisual.

\section{Introdução}

Neste artigo, apresentam-se um mapeamento e uma discussão acerca do emprego dos termos legendagem, legendação e tradução de/ para legendas em textos especializados. 0 mapeamento é realizado em títulos de teses e dissertações de programas de pós-graduação de instituições brasileiras e em artigos científicos publicados eletronicamente. A partir disso, objetiva-se analisar a frequência de uso dos referidos termos com vistas a discutir possibilidades de cunhagem terminológica.

A motivação inicial para essa investigação emergiu das pesquisas de mestrado das autoras deste estudo, período em que se observou a falta de consenso terminológico na literatura da área e até mesmo entre os próprios pares. Alguns pesquisadores faziam distinção entre legendagem e legendação ao passo que outros pareciam ignorar tal variação, o que os levava a usar os termos de forma indiscriminada ou, ainda, a optar por um terceiro termo: tradução de/ para legendas. 
Koglin, A. e OliveiRA, S. M. - Variações terminológicas no campo Tradução Audiovisual: análise dos termos legendação, legendagem e tradução de/ para legendas.

Uma provável explicação para tal quadro poderia ser que, como 0 próprio campo disciplinar Estudos da Tradução ainda se caracteriza por um caráter nômade (PYM 1999; PAGANO \& VASCONCELLOS 2003; FROTA 2007), visto que, no geral, encontra-se vinculado a programas de pós-graduação mais amplos ${ }^{1}$; trata-se de uma área em que a relação entre termos e seus respectivos significados ainda precisa ser consolidada.

Acredita-se que, com o aumento e aprofundamento das pesquisas, uma terminologia com conceitos livres de ambiguidades se faz necessária. Em decorrência disso, a Tradução Audiovisual - com suas diferentes subdivisões² poderá ser verdadeiramente reconhecida como tradução, uma vez que sua identidade ainda é questionada (Frota 2007; SHUTTLEWORTH \& COWIE 1997).

Embora recentemente Franco e Araújo (2011) defendam que a distinção entre os termos legendagem e legendação não mais se sustenta, este estudo se justifica pela necessidade de normalização e reflexão entre os especialistas em legendagem/ /egendação ${ }^{3}$ acerca dos usos da terminologia própria ao campo. Isso porque a "ciência pede à linguagem clareza nas definições e univocidade nas denominações, e a língua portuguesa não pode deixar de ter a palavra nessa evolução." (PEDROSA et al. 2005: 183)

Para o desenvolvimento deste estudo, o artigo está organizado em cinco seções. Na primeira seção, apresenta-se a revisão da literatura; na segunda, a metodologia para coleta e análise dos dados; na terceira, realizam-se a análise e a discussão dos dados; na quarta, discute-se uma proposta de cunhagem terminológica e, por fim, são tecidas as considerações finais.

\footnotetext{
${ }^{1}$ O Programa de Pós-graduação em Estudos da Tradução da Universidade Federal de Santa Catarina (www.pget.ufsc.b), o Programa de Pós-graduação em Estudos da Tradução da Universidade de Brasília (http:// www. postrad.unb.br) e o Programa de Pós-graduação em Estudos da Tradução da Universidade de São Paulo (http:// dlm.fflch.usp.br/traducao) são os únicos até então, no Brasil, que investigam questões de tradução dentro de um programa independente.

${ }^{2}$ Entende-se por tradução audiovisual aquela que é feita para "o cinema, para a televisão ou vídeo, de textos audiovisuais de todos tipos (filmes, documentários, etc) em diversas modalidades: vozes sobrepostas, dublagem, legendação/legendagem e interpretação simultânea de filmes" (tradução das autoras, ALBIR 2002: 77).

${ }^{3}$ Face ao uso indiscriminado dos termos legendação e legendagem em português, neste artigo optamos pela escrita separada por barras.
} 

análise dos termos legendação, legendagem e tradução de/ para legendas.

\section{Revisão da literatura}

A Tradução Audiovisual, como campo de pesquisa acadêmica, vem atraindo cada vez mais pesquisadores (FRANCO \& ARAÚjO 2011) e, segundo Trindade (2003: 185), é "a área de maior alcance na sociedade entre as práticas tradutórias", dentro da qual estão incluídas investigações sobre legendas abertas e fechadas, dublagem e legendação/legendagem.

Frota (2007: 164), ao tratar da "operação que transforma as falas dos personagens de um filme em linguagem escrita das legendas", questiona se tal atividade pode ser considerada tradução. Também Shuttleworth \& Cowie (1997) fazem referência a esse questionamento e afirmam que a legendação/legendagem tem sido amplamente ignorada dentro dos Estudos da Tradução.

$\mathrm{Na}$ circulação de textos especializados do contexto brasileiro, observase a utilização dos termos legendação e legendagem de forma indistinta, apesar de um pequeno grupo de pesquisadores distingui-Ios (ALVARENGA 1998; ARAÚJ O 2002, 2006; OLIVEIRA 2008; KOGLIN 2008). Para tratar disso, as subseções seguintes apresentam: a) discussão acerca da importância da terminologia para a consolidação de uma área de especialidade bem como para comunicação efetiva entre os pares e; b) revisão do percurso diacrônico na literatura em relação ao uso dos termos legendagem/ legendação.

\section{1 A importância da consolidação terminológica}

A leitura e a escrita de textos científicos, usualmente repletos de linguagem técnica, permeiam a comunicação entre os pares no meio acadêmico. A terminologia inerente à cada área de especialidade constitui-se um elemento importante, pois facilita "aos cientistas, técnicos e profissionais 
Koglin, A. e OliveiRA, S. M. - Variações terminológicas no campo Tradução Audiovisual: análise dos termos legendação, legendagem e tradução de/ para legendas.

a comunicação entre si, em sentido restrito, e a divulgação de suas ideias e conceitos, em sentido lato" (FARIAS 2008: 1)

A terminologia de cada área de especialidade tem como característica maior delimitar seus conceitos próprios, além de diferenciá-la da palavra comum, de uso geral tanto por leigos como por especialistas. O termo técnico, conforme Filipec (1976: 55, apud. EMMEL 1998), é uma unidade lexical específica, que designa um conceito definido no sistema de uma área de especialidade.

A consolidação de um termo técnico como tal é determinada pelo contexto e pelo cotexto, isto é, seu novo sentido se estabelece em função do conteúdo textual e da frequência com que ele ocorre. Nesse processo, a forma do termo técnico não muda, apenas lhe é atribuído um novo valor semântico que será deduzido, conforme o assunto do texto. Segundo Emmel (1998), a classe de palavras que mais se destaca na consolidação de termos técnicos é a dos substantivos. Tal conjunto de termos forma a terminologia, cuja função principal é organizar as noções dos termos dentro de cada área de especialidade.

Dessa forma, o uso do termo técnico em publicações científicas é um recurso linguístico que contribui para a sistematização e disseminação da produção de conhecimentos, conforme atesta Krieger (2006: 46).

Um termo não é apenas expressão de um nódulo conceitual das ciências [...], mas é também forte recurso lingüístico de precisão conceitual. 0 uso de termos contribui, em muito, para tornar a chamada comunicação especializada mais obj etiva, menos sujeita a ambigüidades e, conseqüentemente, mais eficiente, por quanto favorece uma compreensão comum sobre os conceitos, objetos e processos expressos pelo componente terminológico.

Ademais, para Cabré (1993), a terminologia possui uma função social, que é auxiliar a comunicação entre os especialistas e o público leigo de forma a superar os obstáculos terminológicos criados pelo contato entre as línguas.

A utilização de termos não cunhados em uma determinada língua, além de causar ruídos na disseminação e compreensão de conceitos entre os 
Koglin, A. e OlivelRA, S. M. - Variações terminológicas no campo Tradução Audiovisual: análise dos termos legendação, legendagem e tradução de/ para legendas.

especialistas, pode ainda criar dificuldades de tradução. Quando o tradutor não domina um assunto específico suficientemente ou quando se trata de textos relacionados à tecnologia de ponta cujos termos ainda não estão cunhados, há dois caminhos possíveis para tradução. Conforme sugestão de Ribeiro (2004), uma possibilidade frequente, que usualmente acontece a pedido dos clientes, é manter os termos em inglês e, na ausência de tal solicitação, cabe ao tradutor apresentar uma tradução para o termo e validálo com o cliente ou com especialistas. Contudo, se não há um consenso de uso dos termos entre os próprios especialistas, o tradutor enfrentará dificuldades adicionais para a realização de sua tarefa e, consequentemente, a disseminação dos conceitos e conhecimentos científicos pode ser prejudicada.

Alvarez (2006: 1), ao se referir à tradução técnico-científica e à terminologia, afirma que "a um significante não pode corresponder mais de um significado e vice-versa". Para Alvarez (2006), a linguagem técnicocientífica caracteriza-se por uma preponderância de designação exata e inequívoca dos conteúdos referidos. Estes se manifestam, do ponto de vista linguístico, através de dois traços essenciais, a saber:

a) a operatividade do princípio de consubstancialidade quantitativa, a associação entre o significante e o significado que deve ser interpretada como uma relação biunívoca, ou seja, a um significante não pode corresponder mais de um significado e viceversa; b) as unidades do léxico técnico-científico não têm valor lingüístico, seu valor é extralingüístico, o domínio nocional de uma ciência está construído e conformado como tal, independentemente da atuação lingüística. (ALVAREZ 2006: 1)

Essa premissa, entretanto, não é observada na área de especialidade legendagem/legendação, em que se pode constatar a utilização de pelo menos três termos (legendagem, legendação, tradução de/ para legendas) nas pesquisas e publicações, conforme levantamento apresentado na seção subsequente. 
Koglin, A. e OliveiRA, S. M. - Variações terminológicas no campo Tradução Audiovisual: análise dos termos legendação, legendagem e tradução de/ para legendas.

\subsection{Legendação, legendagem ou tradução de/ para legendas: impasse terminológico}

A relevância de se discutir, no contexto brasileiro, o emprego dos termos que dão título a essa seção deve-se ao fato de a língua portuguesa possuir duas palavras - legendação/legendagem ${ }^{4}$ - para se referir a ações diferentes. Já o inglês e o espanhol, idiomas nos quais é publicada considerável parte da literatura sobre Tradução Audiovisual, há um único termo em cada língua: subtitling e subtitulación, respectivamente. Assim, discutir e definir o contexto de uso dos termos legendação e legendagem poderá auxiliar inclusive na tradução de textos teóricos oriundos dos dois idiomas supracitados.

Por mais que nos contextos de uso de subtitling e subtitulación esses termos possam aludir ao processo que vai desde a tradução até a inserção das legendas na película, realizado por uma mesma pessoa e, no contexto brasileiro atualmente "a diferenciação entre legendação e legendagem não se sustenta (FRANCO \& ARAÚjO 2011: 6)", defende-se que é necessário chegar a um consenso sobre as relações estabelecidas entre significante e significado.

Em termos teóricos, Alvarenga (1998) é a primeira pesquisadora brasileira a discutir e propor a distinção entre legendação e legendagem. Para essa pesquisadora, legendação é a tradução do texto, enquanto a legendagem é a inserção das legendas na película. Outros pesquisadores (ARAÚ) 0 2002; OLIVEIRA 2008; KOGLIN 2007, 2009, 2011; LIBERATTI 2011) assumem em seus trabalhos essa mesma diferenciação, embora não apresentem uma discussão terminológica explícita.

Araújo (2002: 149), por exemplo, diz que "o tradutor faz a legendação, muitas vezes sem fazer uso do software e o devolve à empresa legendadora [onde] é feita a marcação, a revisão e a legendagem (gravação das legendas na fita)". Ainda que nos dias atuais, dada a disseminação de softwares, seja

\footnotetext{
${ }^{4}$ Em alguns casos, também aparece tradução de/ para legendas como sinônimo de uma e/ ou outra.
} 
viável uma mesma pessoa ser responsável pelo processo completo, advoga-se em favor da necessidade de univocidade dos termos em questão.

Observa-se que, no âmbito das pesquisas acadêmicas, essa carência de uniformidade terminológica tem gerado conflitos, pois, aparentemente, alguns pesquisadores consideram os termos legendação e legendagem como sinônimos. É o que se pode verificar em um artigo de Lima (2009), em que a palavra-chave utilizada é legendação, mas no corpo do trabalho não há qualquer menção a essa palavra e sim à legendagem.

A fim de se ampliar a reflexão acerca do uso dos termos legendagem/legendação nas publicações brasileiras e discutir uma proposta de cunhagem, apresenta-se a seguir a metodologia de levantamento e análise dos dados quantitativos.

\section{Metodologia}

Inicialmente, faz-se necessário esclarecer a natureza e a abrangência do levantamento de dados utilizados neste estudo. Embora a pesquisa aqui realizada seja baseada no cotejamento de diferentes motores de busca, almeja-se apresentar não um mapa do território da Tradução Audiovisual, mas sim um quadro sinóptico do campo legendagem/legendação para fins de investigação dos usos terminológicos nesta subárea. Em função disso, 0 mapeamento não assegura uma pesquisa exaustiva em relação às produções científicas no campo da Tradução Audiovisual.

Isso posto, apresentam-se, na sequência desta seção, a metodologia de coleta dos dados e a de análise empregadas para mapear as opções terminológicas utilizadas nas pesquisas relacionadas à legendagem/legendação. 
Koglin, A. e OliveiRA, S. M. - Variações terminológicas no campo Tradução Audiovisual: análise dos termos legendação, legendagem e tradução de/ para legendas.

\section{1 Metodologia de levantamento dos dados}

Levando-se em consideração a disseminação das publicações em formato eletrônico, em um momento inicial o levantamento de dados foi feito diretamente no banco de teses e dissertações dos programas de pósgraduação ${ }^{5}$ com trabalhos desenvolvidos em Estudos da Tradução. Com base no recorte de pesquisa, isto é, legendagem/legendação, a busca por teses e dissertações defendidas ${ }^{6}$ nesta subárea foi realizada com base em três termos pré-determinados: legendação, legendagem, legenda(s), que foram buscados nos títulos dos trabalhos. No caso do último termo, legenda(s), devido ao seu caráter polissêmico, a pesquisa levou em conta também a leitura do resumo para garantir que se tratava de trabalho da área Estudos da Tradução. Além disso, foram contabilizados, neste estudo, apenas os termos que apareciam em trabalhos relacionados à tradução interlingual.

O ponto de partida para a seleção dos programas de pós-graduação foi a apresentação de dados feita por Pagano e Vasconcellos (2003), em um gráfico que mostra a distribuição de teses e dissertações com enfoque de pesquisa na tradução em diferentes instituições de ensino superior (IES). Tomando como base os dados do CD-ROM Estudos da Tradução no Brasil, publicado em 2001, a investigação dessas pesquisadoras apresenta um balanço dos Estudos da Tradução no contexto brasileiro com referência a modalidades de pesquisa e tendências quanto à afiliação teórica dos trabalhos.

Em função do razoável intervalo de tempo desde a publicação do mapeamento de Pagano e Vasconcellos (2003) até o presente momento e da crescente expansão dos estudos no campo da tradução associado à incompletude nos bancos de teses e dissertações disponibilizados pelas IES, optou-se por expandir a busca em outros mecanismos de pesquisa no meio eletrônico. Iniciou-se com o banco de teses e dissertações (BDTD) fornecido

\footnotetext{
${ }^{5}$ Convém salientar que, conforme informado no site, a Biblioteca Digital da PUC-SP, disponibiliza em formato eletrônico inicialmente as teses e dissertações defendidas a partir de 2005. Indica-se ainda que o acervo retrospectivo será inserido gradativamente.

${ }^{6}$ Esta pesquisa foi realizada durante os meses de fevereiro e março de 2013.
} 
Koglin, A. e OlivelRA, S. M. - Variações terminológicas no campo Tradução Audiovisual: análise dos termos legendação, legendagem e tradução de/ para legendas.

pelo site do IBICT, porém como apresenta incorreções visíveis (também observadas por Frota, 2007), foi realizado um cotejamento dos dados já encontrados com aqueles disponibilizados por outros dois bancos de teses e dissertações: o domínio público (www.dominiopublico.org.br) e o Sistema de catálogo online nacional (SABI).

Considerando que as publicações existentes não são necessariamente vinculadas a pesquisas desenvolvidas nos cursos de mestrado e doutorado, optou-se por expandir a busca em títulos de artigos científicos. Para isso, foram utilizados os mesmos termos - legendação, legendagem, legenda(s) -, com o cuidado de contabilizar apenas os trabalhos publicados no contexto da tradução interlingual e no âmbito nacional. Também foram desconsiderados os registros repetidos, isto é, os casos em que o mesmo artigo estava publicado mais de uma vez em sites distintos.

\subsection{Metodologia de análise dos dados}

A análise dos dados é realizada com base em seus aspectos quantitativos e qualitativos. Quantitativamente, a análise é utilizada para a) definição do número de trabalhos publicados nas diferentes IES, b) distribuição terminológica entre artigos, teses e dissertações e c) embasamento para construção de uma proposta de cunhagem terminológica. Qualitativamente, os dados são usados para discussão das variações semânticas em relação aos termos investigados.

\section{Análise e discussão dos dados}

Após a busca com o cotejamento de diferentes sistemas de busca online, foi encontrado um total de 27 trabalhos, incluindo-se teses e dissertações. A distribuição destes trabalhos por IES pode ser visualizada no gráfico 1. 
Koglin, A. e OliveirA, S. M. - Variações terminológicas no campo Tradução Audiovisual: análise dos termos legendação, legendagem e tradução de/ para legendas.

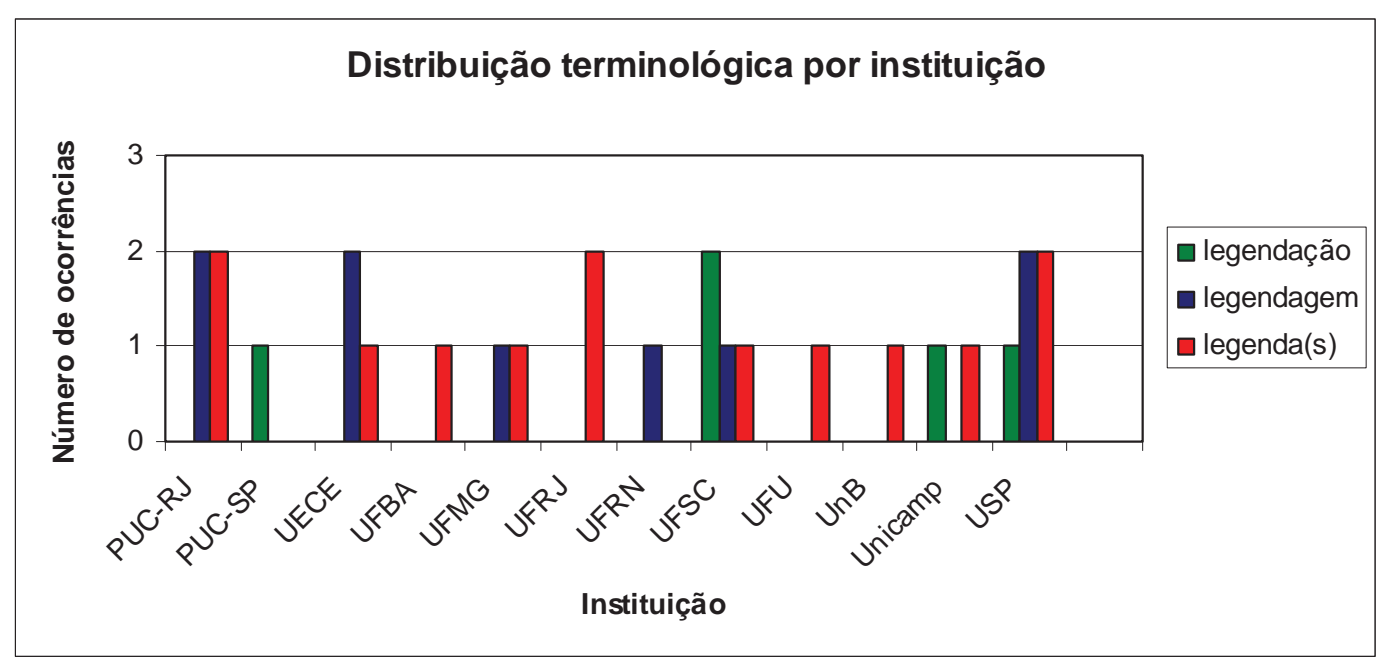

Gráfico 1: Distribuição terminológica nas diferentes IES

Como se observa no gráfico 1 , foram encontrados registros de trabalhos desenvolvidos com a utilização dos termos legendagem/legendação/legenda(s) em 12 IES distintas. As únicas instituições em que se observaram publicações de teses e dissertações com o uso dos três termos (legendagem, legendação e legenda(s)) são a UFSC e a USP. Já publicações com menção apenas à legendação incluem trabalhos desenvolvidos na PUC-SP. Legenda(s), usualmente vinculada aos termos compostos tradução de legendas ou tradução para legendas, é o termo com maior abrangência nas IES observáveis no gráfico, à exceção da PUC-SP e da UFRN.

Essa aparente preferência pelo uso de tradução de/para legendas poderia ser explicada pelo fato de a subárea legendagem/legendação ainda ter sua identidade questionada (Frota 2007; Shuttleworth \& Cowie 1997). Assim, o uso do termo tradução associado ao termo legendas nas teses e dissertações encontradas poderia ser uma tentativa de garantir a inserção da pesquisa no campo disciplinar Estudos da Tradução.

Ao considerar o total de teses e dissertações publicadas, constatou-se que quase metade (48\%) delas utiliza o termo tradução de/ para legenda(s), conforme se observa no gráfico 2. 


\section{Distribuição terminológica nas teses/dissertações}

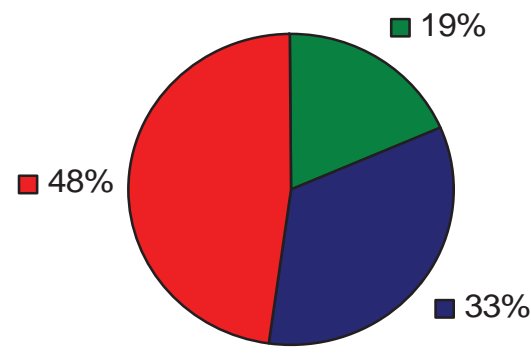

Gráfico 2: Número relativo da distribuição terminológica em teses/ dissertações

O gráfico 2 mostra que, do total de 27 teses e dissertações, cinco utilizam, no título, o termo legendação, nove usam o termo legendagem e a maioria, 13 trabalhos, emprega tradução de/ para legenda(s).

Considerando que, após as defesas das pesquisas de mestrado e doutorado, existe a tendência de se dar continuidade ou iniciar novos estudos a partir de uma postura mais amadurecida em termos de percursos teóricos, expandiu-se a presente pesquisa também para o âmbito de artigos publicados.

Similarmente ao encontrado nas teses e dissertações, o número de artigos publicados é mínimo; porém, observa-se uma tendência diferente quanto ao uso terminológico, como mostra o gráfico 3. 
Koglin, A. e OliveIRA, S. M. - Variações terminológicas no campo Tradução Audiovisual: análise dos termos legendação, legendagem e tradução de/ para legendas.

\section{Distribuição terminológica em artigos}

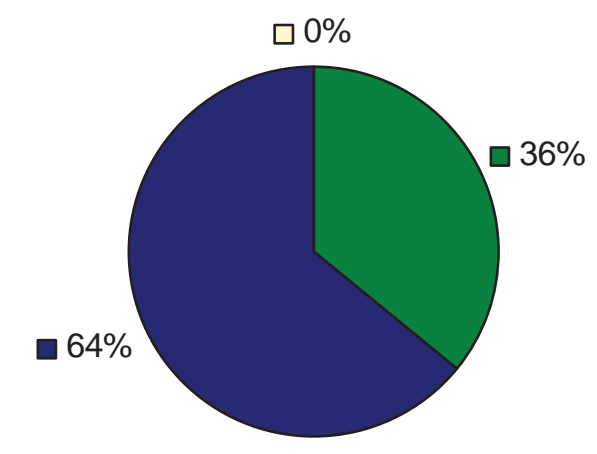

Gráfico 3: Número relativo da distribuição terminológica em artigos

Ao contrário dos dados observados no gráfico 2, o gráfico 3 mostra a ausência do termo tradução de/ para legenda(s). Quanto ao uso de legendação e legendagem, a tendência numérica se mantém, ou seja, cinco registros de legendação e nove registros de legendagem.

Além das diferentes tendências em relação ao uso dos termos durante a comparação entre teses/ dissertações e artigos, também observou-se que, em um mesmo trabalho, há uso indiscriminado de termos. No título da publicação, por exemplo, é utilizado o termo legendação e nas palavras-chave ou no corpo do resumo é usado apenas legendagem ${ }^{7}$, o que sugere que 0 autor considera os termos sinônimos. Do ponto de vista da produção e disseminação do conhecimento, as principais consequências da falta de uniformidade terminológica constatada no ramo da legendagem/legendação são a impossibilidade de comunicação efetiva entre os especialistas e a dificuldade de tradução para publicação em outras línguas que não a oficial do Brasil. Esse quadro, por sua vez, leva a uma estagnação na divulgação do conhecimento, visto que a produção científica dos especialistas da área está

\footnotetext{
7 Lembramos que, embora o foco do mapeamento tenha sido o título das publicações, a pesquisa levou em conta também a leitura do resumo para garantir que se tratava de trabalho da área Estudos da Tradução. Em função disso, foi possível observar o uso indiscriminado de termos dentro de um mesmo trabalho.
} 
suj eita à interpretações múltiplas e equivocadas ou, até mesmo, a limitações na publicação para outras línguas face ao caráter não unívoco do termo.

Ainda que Franco e Araújo (2011) apontem que a diferença entre legendação e legendagem não se sustente nos dias atuais, uma vez que uma mesma pessoa pode realizar os dois procedimentos, qual seja: traduzir e gravar as legendas na película, acredita-se que como se trata de um campo de pesquisa acadêmica, faz-se necessário cunhar e consolidar um sistema de denominação específico, pois a terminologia, "além de organizar 0 pensamento [é a forma com que] os especialistas transferem o conhecimento sobre uma matéria, em uma ou mais línguas (CABRÉ 1999: 213)." Em face disso, discutem-se, na seção subsequente, alternativas em direção à padronização terminológica.

\section{Uma proposta de cunhagem terminológica: horizontes possíveis}

Após o término do mapeamento anteriormente apresentado, optou-se por consultar dicionários a fim de verificar se os termos legendagem e legendação estavam registrados como entradas e com qual definição. Com isso, almejou-se trilhar um caminho, ainda que preliminar, em direção a possibilidades de cunhagem terminológica.

No dicionário Michaelis ${ }^{8}$ - versão online - encontrou-se a seguinte definição para o termo legendação:

Sf (legendar+ção) J orn Ato ou efeito de legendar

8 http://michaelis.uol.com.br/ Não foi encontrada nenhuma entrada para o termo legendagem. 
Koglin, A. e OliveiRA, S. M. - Variações terminológicas no campo Tradução Audiovisual: análise dos termos legendação, legendagem e tradução de/ para legendas.

Cabe esclarecer que a abreviatura "Jorn" refere-se à jornalismo, ou seja, o dicionário não faz menção à legendação no contexto da Tradução Audiovisual. Além disso, a explicação "ato ou efeito de legendar" exige uma predefinição do que seja legendar. Veja-se o que o mesmo dicionário apresenta:

(legendatar2) vtd J orn Colocar legenda, acepções 1 a 4.

Nota-se que, apesar de mencionar quatro possíveis acepções, a abreviatura que remete o termo à área jornalística se mantém.

Voltando à definição de legendação como "ato ou efeito de legendar" e considerando o escopo da tradução, percebe-se que o termo tanto poderia referir-se ao processo tradutório, à tradução já concluída ou mesmo à gravação das legendas na película. Por outro lado, como a entrada faz menção à área jornalística, é duvidoso relacioná-la com o contexto da tradução.

Ainda com respeito ao termo legendação, encontrou-se a seguinte definição no dicionário Aulete:

1. Art.gr. Cin. Telv ${ }^{9}$. Ação ou resultado de legendar (legendação dos quadrinhos; legendação do filme; legendação da fita); LEGENDAGEM

[PI. : -ções]

[F. : legendar -+ -ção]

Constata-se que as acepções apresentadas por esse dicionário fazem alusão ao uso do termo no contexto da Tradução Audiovisual (legendação do filme, da fita). E, apesar de não deixar claro a que parte do processo o termo se refere, indiretamente remete ao termo legendagem se considerada a distinção inicialmente proposta por Alvarenga (1998). O termo legendagem, por sua vez, aparece definido da seguinte forma:

\section{${ }^{9}$ http:// aulete.uol.com. br/ legendação\#ixzz2NzZ8IfyB}


Koglin, A. e OlivelRA, S. M. - Variações terminológicas no campo Tradução Audiovisual: análise dos termos legendação, legendagem e tradução de/ para legendas.

1. Art.gr. Cin. Telv ${ }^{10}$. Feitura e colocação de legendas (legendagem gráfica; legendagem cinematográfica); LEGENDAÇÃO

[PI.: - gens]

[F.: legenda - +-agem1]

Nessa entrada, a definição de legendagem como "feitura e colocação de legendas" sugere uma referência tanto ao processo tradutório como à inserção das legendas na película.

Outro fato observado nas entradas para legendagem e legendação, no dicionário Aulete, é apresentação dos termos como um sendo sinônimo do outro em ambas entradas.

Esse quadro demonstra claramente que a consulta a dicionários não especializados tampouco auxilia pesquisadores e, sobretudo, tradutores da área da Tradução Audiovisual a definirem seus termos. Isso posto,

[...] convém atentar para o facto de que o emprego indevido ou distorcido de conceitos em voga e a incorrecção linguística na tradução / adaptação de termos têm contribuído para a difusão e perpetuação de erros ou equívocos conceptuais e/ ou terminológicos. (FARIAS 2008:2)

Diante disso e face à indefinição terminológica observada na literatura corrente, mostra-se relevante um posicionamento das autoras acerca do termo com maior probabilidade de ser cunhado como termo técnico. Inicialmente, tende-se a concordar com Franco e Araújo (2011) que a distinção proposta por alguns especialistas (Alvarenga 1998; Araújo 2002) entre legendagem e legendação não mais se sustenta diante da possibilidade de uso de softwares que permitem a um só indivíduo realizar o processo completo (tradução, marcação e inserção da legenda na película). No entanto, é premente a necessidade de se estabelecer uma taxonomia unívoca para consolidação desse campo de pesquisa.

${ }^{10}$ http:// aulete.uol.com. br/ legendagem\#ixzz2NzaiKHKa 
Koglin, A. e OliveiRA, S. M. - Variações terminológicas no campo Tradução Audiovisual: análise dos termos legendação, legendagem e tradução de/ para legendas.

Diante da necessidade de escolha, acredita-se que legendagem seja um candidato promissor à cunhagem enquanto nomenclatura técnico-científica da área por três razões: estudos lexicais, distribuição terminológica na literatura corrente (frequência de uso) e preferência de uso entre os profissionais da área.

A utilização da forma com sufixo -agem em detrimento de -ção parece promissora ao se levar em conta estudos linguísticos relativos à formação lexical. Nesse sentido, Gonçalves (2009: 133) identificou amplo grupo de palavras em que o acréscimo do sufixo -agem corresponde "a um agente ou elemento relacionado a uma atividade específica e que designam genericamente a atividade (por exemplo, enfermeiro/ enfermagem)." Este estudo justificaria a consolidação de legendagem para designar atividade de tradução e inserção de legendas como um processo específico e único.

Se considerados os dados relativos à distribuição terminológica em teses, dissertações e artigos científicos em que houve predominância de uso de legendagem, este termo também se mostra com maior inclinação a ser aceito pela comunidade acadêmica.

Essa suposta preferência por legendagem se mantém também na comunidade profissional. Ao ser questionada sobre a distinção entre legendação e legendagem, Martinez, durante entrevista concedida à revista In-Traduções (MATIELO \& COLLET 2011: 98), em cujo texto é apresentada como experiente tradutora para legendas, afirma que nunca ouviu falar em legendação, exceto no contexto acadêmico por meio dos trabalhos de Araújo (2002) e Alvarenga (1998).

Um aspecto importante na constituição da terminologia é que o termo técnico-científico seja aceito pelos especialistas da área com vistas à compreensão entre os pares e à utilização correta dos termos nos meios habituais de expressão da área de especialidade (ALVAREZ 2006). Pode-se considerá-los elementos chave na constituição e na produção do saber em qualquer área, pois devem permitir a comunicação entre especialistas de contextos linguísticos múltiplos. 
Koglin, A. e OliveirA, S. M. - Variações terminológicas no campo Tradução Audiovisual: análise dos termos legendação, legendagem e tradução de/ para legendas.

\section{Considerações finais}

Este estudo se propôs a mapear, com base em pesquisa nas publicações existentes e em discussões prévias observáveis na literatura especializada, a distribuição terminológica dos termos legendagem, legendação e tradução de/ para legendas. Conforme mencionado na metodologia deste trabalho, a representatividade deste mapeamento em termos numéricos pode ser considerada limitada, porém deve-se levar em conta o fato de que estudos neste campo ainda se encontram em estágio germinal no contexto brasileiro.

Diante disso, salientamos que 0 mapeamento e a discussão terminológica aqui realizados no âmbito da legendagem/legendação não tiveram a pretensão de serem exaustivos ou de encerrarem essa questão, mas sim de proporem

um ponto de partida para 0 debate sobre 0 assunto entre pesquisadores e profissionais da área, academia e mercado, com 0 intuito de chegarmos a um consenso e afinarmos o discurso dentro do campo da tradução audiovisual em nosso país, campo esse que vem despertando interesse cada vez maior [...] (FRANCO \& ARAÚ] 0 2011: 20).

Ao se estabelecer um paralelo com o campo disciplinar Estudos da Tradução, em que a Tradução Audiovisual está inserida,

desde sempre, e em todos os tempos e lugares, teóricos e praticantes têm dito o que pensam da tradução, do que ela é ou do que deveria ser. São opiniões que em muitos casos se contradizem, se desdizem, não só no acessório como no essencial [...] (CAMPOS 2004: 11).

Entretanto, para que a disciplina e suas subáreas se consolidem enquanto campo de estudo, é premente a necessidade de se estabelecer um consenso no uso da terminologia que Ihe é intrínseca inclusive nas subáreas que Ihe compõe. 
Koglin, A. e OliveiRA, S. M. - Variações terminológicas no campo Tradução Audiovisual: análise dos termos legendação, legendagem e tradução de/ para legendas.

A falta de consenso terminológico pode ainda ocasionar impasses de tradução dentro da própria disciplina. Tomemos como exemplo o caso do Dicionário de Estudos de Tradução (Dictionary of Translation Studies), cuja entrada relacionada à legendagem (subtitling), se traduzida para o português, provavelmente geraria conflitos na tradução, face à não univocidade de utilização dos termos na literatura brasileira especializada. Isso porque uma estratégia comumente utilizada por tradutores, quando desconhecem a terminologia que estão traduzindo, é consultar publicações especializadas para buscar o termo já consolidado.

Para concluir, acreditamos que,

Se o intuito é aprofundar os estudos e investir cada vez mais na qualidade dos produtos audiovisuais traduzidos oferecidos aos espectadores brasileiros, a homogeneidade gráfica, terminológica e conceitual é condição sine qua non para introduzir qualquer diálogo entre pesquisadores e profissionais na área. (FRANCO \& ARAÚjO 2011: 20)

\section{Referências bibliográficas}

ALBIR, A. H. Traducción y traductología: introducción a la traductología. Madri: Cátedra, 2002.

ALVARENGA, L. Subtitler: legendador ou legendista? In: BREZOLIN, A. et all (org.) Anais do I Congresso Ibero-Americano de Tradução e Interpretação. São Paulo: 1998, pp. 214-216.

ALVAREZ, M. L. O. A tradução técnico-científica no contexto Latinoamericano. In: Anais da 58a Reunião da SBPC. Florianópolis, Santa Catarina, 2006.

ARAÚj O, V.L.S. Glossário bilíngüe de clichês para legendagem e dublagem. The ESPecialist, v.23, n.2, pp.139-154, 2002.

. O processo de legendagem no Brasil. Revista do GELNE, Fortaleza, v. 1/2, n. 1, pp. 156-159, 2006.

BENVENISTE, É. Problemas de lingüística geral II. Campinas: Pontes, 1989.

CABRÉ, M. T. La terminología: Barcelona: Antártida, 1993.

- La terminología: representación y comunicación. Barcelona: Universitat Pompeu Fabra, 1999. 
Koglin, A. e OliveIRA, S. M. - Variações terminológicas no campo Tradução Audiovisual: análise dos termos legendação, legendagem e tradução de/ para legendas.

CAMPOS, G. O que é tradução. São Paulo: Brasiliense, 2004.

EMMEL, I. O "fazer" terminológico X o "fazer" tradutório: uma aplicação prática na área de especialidade tradutologia. 1998. $153 \mathrm{f}$. Dissertação (Mestrado em Lingüística) - Pós-Graduação em Lingüística, Universidade Federal de Santa Catarina, Florianópolis.

FARIAS, L. A terminologia e sua importância para os cientistas e profissionais da informação. 2008.2 Disponível em: http:// www.ccje.ufes. br/ arquivologia/ deltci/ textosterminologia. htm . Acesso em: 10 mar 2013.

FRANCO E. P. C. \& ARAÚJO V. L. S. Questões terminológico-conceituais no campo da tradução audiovisual (TAV). Tradução em Revista, v. 2, pp. 1-23, 2011.

FROTA, M. P. Um balanço dos estudos da tradução no Brasil. Cadernos de Tradução, n. 19, v. 1, Florianópolis, 2007, pp. 135-169.

GONÇALVES, A. A. G. Estudo da significação do sufixo -agem em vocábulos do século XX. In: ALVES et al (org.). Os estudos lexicais em diferentes perspectivas. São Paulo: FFLCH/ USP, 2009, pp. 120-134.

LIBERATTI, E. Legendação de séries humorísticas: um estudo da tradução do humor na série americana "Friends". Scientia Traductionis, n.9, 2011, pp. 218-234.

KOGLIN, A. Barreiras culturais e desafios técnicos na legendação e na tradução técnica. Revista Querubim, n. 5, ano 3, 2007, pp. 12-19.

- A tradução de metáforas geradoras de humor na série televisiva Friends: um estudo de legendas. 2008. 99 f. Dissertação (Mestrado em Estudos da Tradução) - Pós-Graduação em Estudos da Tradução, Universidade Federal de Santa Catarina, Florianópolis.

- A tradução da linguagem de baixo calão em obras fílmicas: um estudo baseado em corpus. Actas de las II J ornadas Internacionales de Traductología. Facultad de Lenguas, UNC, Córdoba, Argentina, 2009, pp. 1-8.

- Papel da competência leitora na compreensão da linguagem metafórica em obras legendadas. Actas del XVI Congreso Internacional de la ALFAL, Alcalá, 2011, pp. 2929-2934.

KRIEGER, M. G. Terminologia técnico-científica: políticas lingüísticas e Mercosul. Ciência e Cultura, n. 2, v. 58, São Paulo, 2006, pp. 45-48.

LIMA, J. C. . O tradutor legendista em Cidade de Deus. In: Estudos Linguísticos, n. 38, v.2, São Paulo, 2009, pp. 367-378.

MATIELO, R. \& COLLET, T. Entrevista com Sabrina Martinez. In-Traduções, n. 4, v. 3, 2011, pp. 96-100.

OLIVEIRA, S. M. Legendação de metáforas: um estudo empírico-experimental com base no filme La Lengua de las Maripas. 2008. $101 \mathrm{f}$. Dissertação 
Koglin, A. e OliveiRA, S. M. - Variações terminológicas no campo Tradução Audiovisual: análise dos termos legendação, legendagem e tradução de/ para legendas.

(Mestrado em Estudos da Tradução) - Pós-Graduação em Estudos da Tradução, Universidade Federal de Santa Catarina, Florianópolis.

PAGANO, A.; VASCONCELLOS, M. L. Estudos da tradução no Brasil: reflexões sobre teses e dissertações elaboradas por pesquisadores brasileiros nas décadas de 1980 e 1990. D.E.L.T.A., n. 19, especial, 2003, pp. 1-24.

PEDROSA, F. et al. Dar a palavra à ciência: diálogos entre linguística e linguagens de especialidades a propósito de um dicionário terminológico. In: Estudos em homenagem ao professor doutor Mário Vilela. Porto: Faculdade de Letras da Universidade do Porto, 2005, pp. 181-192.

PYM, A. Why Translation Studies Should Learn to be Homeless. In: Martins, M. A. P. ed. Tradução e Multidisciplinaridade. Rio de Janeiro/RJ: Lucerna, 1999, pp. 35-51.

RIBEIRO, G. C. B. Tradução técnica, terminologia e lingüística de corpus: a ferramenta Wordsmith Tools. Cadernos de Tradução. Florianópolis: PGET, 2004, v.2, n.14, pp. 159-174.

SHUTTLEWORTH, M.; COWIE, M. Dictionary of Translation Studies. Manchester, UK: St. J erome, 1997.

TRINDADE, E. In: BENEDETTI, I. C. \& SOBRAL, A. (Org.) Conversas com tradutores: balanços e perspectivas da tradução. São Paulo: Parábola Editorial, 2003. 